\title{
Talking Architecture: Exploring knowledge production through conversation in architectural creative practice research
}

DR ELI HATLESKOG, University of Ljubljana

DR ANNA HOLDER, Aarhus School of Architecture

ANTHONY HOETE, WHAT architecture / RMIT

\begin{abstract}
This paper will discuss the field of Architectural Creative Practice Research (ACPR) with a view to understanding what architects actually do in practice and how what they do may be translated into creative practice research. It argues that, since it is an entrepreneurial profession, a lot of what architects do is talk, but that we do not usually think of talking as a design skill or research method.
\end{abstract}

However, talking about architecture is not just words. Not only can it can inform the production of built form, it can allow for nuanced and diverse views of practice to be shared and developed.

This paper will argue that talking about architecture (and not simply drawing it or writing about it) can help us to develop greater understandings of both the role of the architect in practice and the diverse opportunities that an architectural response to creative practice research may provide.

\section{KEYWORDS}

Talking Architecture, Architecture Creative Practice Research (ACPR), Relational Knowledge. 
Voice 1:

When I was at architecture school, a tutor told me that perhaps I was going to be the kind of architect who didn't design buildings. I don't think it was meant as a compliment, but, nevertheless, I took it as one. I guess for me it isn't really about buildings, we probably already have more than enough of them, there is much more to practice, which I suppose leads into question: what is it that architects actually do?

\section{Introduction}

The question of architecture is not simply a question of design and construction. For every built structure, there are many times more projects that were never realized. In turn, each building is an expression (not least) of: intention, will, drive, perseverance, pragmatism and compromise. Over the past twenty years, there has been a growing movement toward recognising the production of knowledge through the medium of architecture, not merely through writing and reflection, or measurement, but doing practice as research (Van Schaik and Johnson 2011). It can be argued that this movement has been greatly inspired by the arts and design (Frayling 1993) and is now a fairly well established method of research amongst architects. Given that inspiration has been taken from the arts and design, there can be a tendency to focus attention upon the product, process and person (Cross 2001). However, if doing architecture is not simply about the architect and his/her pursuit of built form, then, it seems certain that doing architectural creative practice research (ACPR) can be about a whole lot more than personalities and buildings.

There is, however, a great deal of romanticism within the architectural profession as to the architect's role; budding architects have been taught that they should aim to become individual design 'stars' (Gutman, 1988) and the myth of the hero-genius pervades (Till 1998, 2009). This industrialist mind-set, relating to the self-actualising individual/romantic loner, does not, however, appreciate the richness of knowledge that can be developed through doing ACPR.

This paper was developed through collaboration between three creative practice researchers, who are all architects, in response to group interviews staged with other creative practice researchers. These interviews revealed to us that the act of talking is more than simply a means of sense making: it is also a generative and creative act across practice and research. Furthermore, since many of those we talked to were architects, we noted that there was a way of talking and use of 'jargon' or specific terminology that seemed to be specific to the profession. Rather than try to take a generalist approach to creative practice research, we suggest that the architecture profession can develop understanding of methods within architectural creative practice research by paying attention to the set of traditions, assumptions and forms of 
communication particular to architecture practitioner-researchers, which do not necessarily apply across the broader field of creative practice research.

Where a fascination in designers, design processes and designed artefacts can form a part of ACPR, there is much work yet to be done with regard to the other things that architects do. Furthermore, it may be argued that what architectural design is, is not particularly interesting. (Fry 2015) What can be interesting, however, is what architectural design can do: the relationships, negotiations and interpretations it prompts, creates and develops.

In order to develop knowledge through practice, creative practice researchers can reflect upon their practice with the aim of explicating some of the tacit knowledge therein. From our experience, it would appear that these reflections largely take the form of stories and anecdotes which are shared and develop. As such, it may be suggested that the acts of talking do not simply help to explicate knowledge, but allow for new knowledge to be developed relationally between those doing the talking.

In this paper, the voices of the authors, reflecting on their experiences from architecture school, working in practice and undertaking research, are presented, as Voices 1,2 and 3, in conversation within the main body of the text. Supporting voices, taken from conversational interviews staged with 17 different creative practice researchers linked to the European Architecture, Design and Art Practice Trainingresearch Initial Training Network (ADAPT-r ITN) are presented in footnotes where they provide the empirical basis for observations developed within this article. These conversational interviews elicited reflections and observations from architects and landscape architects at different stages in their careers, from $\mathrm{PhD}$ candidates and doctorate holders to practitioner-academics now supervising creative practice research.

Conversations about architecture need not depend upon the production of built form, but can allow for nuanced and diverse views of practice to be shared and developed. This paper will argue that talking about architecture (and not simply drawing it or writing about it) can help us to develop greater understandings of both the role of the architect in practice and the diverse opportunities that an architectural response to creative practice research may provide.

\section{Architects in practice: doing 'design' and what else?}

There are a number of myths that surround the architectural profession; perhaps the most 
enduring is that of the architect as hero. (Gardner 2011) This myth relates to a man ${ }^{1}$ who has some unfathomable talent for designing buildings. He is touched by genius and works alone:

There still is a powerful image in the profession which encourages the architect to think of himself as a free, independent practitioner, operating more or less on his own, and cultivating personal relationships with an understanding and appreciative client. (Gutman 1988, 37)

There is also an accompanying appearance and attitude:

We all know that architects are well paid, wear black (or sometimes more daringly red), and if possible ignore their clients so that they can design what they want. (Dobson, 2014, 21)

Of course, the idea of the architect working in isolation is inaccurate. There are many different people and professions involved in the design and construction of any given project (Edwards Campkin and Arbaci, 2009; Cuff 1991). Furthermore, rather than feeling they can ignore their clients, many architects are actually intimidated by them. (Cuff 1991, 40) So why this need to 'posture' as a powerful and controlling individual integral to the production of the built environment? Perhaps it is an attempt to try to remain relevant as the architect's role is shrinking just as other specialist roles proliferate. And yet, some architects continue to both speak and write in rarefied ways, which seem exclusionary at best.

\section{Voice 1:}

Yes, but you do hope they are just putting it on, do they really mean what they're saying? I'd like to give them credit and think that it's them being playful. Otherwise, if it's an involuntary behaviour, then I'd say that's a problem. But you would hope you would have enough self-awareness to see it, if you were speaking this way, I mean.

\section{Voice 3:}

I suppose I can see the appeal: at architecture school, when they told us to look at books of beautiful works and understand that this all came about due to this one charismatic, talented, creative person. It's a more seductive idea than the messy

1

For example all previous winners of the RIBA gold medal are men, or husband and wife partnerships: https://www.architecture.com/RIBA/Awards/RoyalGoldMedal/RoyalGoldMedal.aspx [online]. Accessed 20 July 2015. 
reality: waiting for the phone to ring, losing out on jobs at the last minute because you've been honest about the time it will take to design it and that makes you too expensive compared to all your competitors... And then the confusion of working for 'multi-headed' clients, the politics of who you listen to in developing the brief, particularly if you're trying to take the needs of different user groups into account as well. No, it's much easier to pretend that it's all about the architect and their 'pure' vision!

By obfuscation and speaking in jargon-riddled tongues, are architects trying to elevate themselves above the 'lay public' by adding mystique to the processes of architecture? (Meades 2012, 10)

Since the 1990s, however, that very 'lay public' has been empowered through the free availability of affordable media technologies and information online, so the idea that the architectural profession can be a bastion of knowledge, which the architects somehow control and distribute, is in itself outmoded. New media have resulted in, 'an explosion of self-initiated cultural production.' (Meissen and Basar 2006, 23) For example, for those wishing to design their dream home, there are websites providing instruction, inspiration, tools and software, negating the need for an architect, or equivalent professional entirely. ${ }^{2}$

Whilst this may appear to suggest a crisis in the profession, it also suggests that architects can look to aspects other than heroic design processes, with a view to understanding and developing knowledge in practice.

The emphasis on the design processes leads into another myth popular to the architectural profession. This is the myth that architects spend the majority of their time designing buildings. Robert Gutman, in his comprehensive survey of the US architecture industry, argues that this is not the case; in reality the design of buildings is a minor part of the working day and, 'studies have shown that no more than 10 percent of work time in an office is spent on [designing buildings]' (Gutman 1988, 44).

Assuming that architects primarily design buildings limits understanding of what architects actually do. Of course, the design of buildings is part of the profession, but there are other aspects to practice. In turn, it may be argued that these other aspects

2

For example, see: 'print your own home' https://wikihouse-cc.appspot.com [online] Accessed 20 May 2015. 
also rely on design, not as an output, but as a process or skill (Lawson 1980, 14). Design is not simply an action, it is also a mind-set and approach.

By taking a broad view of practice and looking for knowledge beyond that which leads to constructed buildings, what is it that is particular to the architectural profession? Is it an understanding of: planning, surveys, fees, contracts, tendering, management and 'snagging' (RIBA 2013) Does it go beyond these to: marketing, bidding, branding, public relations, advertising and award entries? (RIBA 2010). Is it that the architect goes out and engages with the world, as an entrepreneur? ${ }^{3}$ (Gutman 1988) Or does the architect work as a mediator in between concerns, constrictions and contexts? (Rose 2013)

By looking at diversity, it becomes clear that an architectural response to practice is not universal or fixed, but depends entirely upon the role that the architect chooses to take with regard to the various contexts of practice. This role may, for example, be framed with regard to what type of practice (local/star/niche/regional/interdisciplinary/etc. (RIBA 2005)) or sector (commercial/housing/education/healthcare (Dobson 2014, 47)) he/she wants to pursue. However, increasingly many architects do not limit themselves to these traditional domains and practice outwith the confines of the discipline.

It is thought that at any one time up to a third of UK architects on the register managed by the Architects Registration Board (ARB) are not currently involved in activity that might recognisably conform to a traditional model of architectural practice. (Dobson 2014, 12)

As such, when not engaging in traditional models of practice, architects can take on diverse roles. A recent survey by European research platform Wonderland recorded that other services architects provide include: teaching, graphic and webpage design,

3

The architect as entrepreneur

Extracts from conversational interviews staged in the spring of 2015:

Putting yourself out in is definitely part of building substrata of practice... through all sorts of engagements and activities... you create a multimodal practice, which allows you to spring from that into moments of particular creative practice that are quite diverse in their outputs.

Practice is not a matter of putting a sign up and waiting, it's a matter of actually becoming active.

Following the economic crisis in 2008, [they] were sitting there going, what are we going to do? So, they started combing the newspapers and they would apply for anything. There was a thing at Antwerp for installing lighting in the sewers, so that tours could go down there. They applied for that and in bidding for it they said, well, what we are going to do is put miners helmets on everybody so they have got a light and then we can take the money for the lighting and we can make a room where you go and you get into waders and then you go wading through the sewers [...] and then you come back and you decontaminate. It turned from a lighting project into an architectural project. There is a type of that kind of knowledge that comes out of this. 
journalism, and event management. $(2012,50)$ This suggests that architects now feel liberated, or required, to practice across a field, where their activities might include:

setting up an architecture center, a festival or a magazine, $[\ldots]$ the production of a book [...] [...] exploring cross-disciplinary fields of work [...] social engineering, [...] incentives and support for neighborhood initiatives, urban agriculture, workspaces for new creative businesses, workshops for youths and children, street festivals and other events that lie outside the domain of traditional architecture. (Wonderland 2012, 244)

An appreciation of diversity in practice shows that there can be much more to architecture than a traditional understanding of the hero/genius designer gives credit to. Architects can do a whole lot more than just designing built form. In turn, by releasing architectural practice from the notion that it is mainly about individual autonomy and a traditional understanding of design, practice (and research) can be understood more broadly as a field, where the competences, knowledge and creativity of the respective practitioners are framed in such a way that invention, innovation and learning can occur. (Amin \& Cohendet 2004, 2) ${ }^{4}$

\section{Architectural Creative Practice Research (ACPR)}

\section{Voice 1:}

Perhaps, to be an architect means you also have to sign up to a particular set of values. It's about recognition, or rather where you seek recognition, who you seek recognition from. Where and how you choose to promote yourself, which competitions you enter, or clients you take on.

\section{Voice 2:}

4

Layers of practice

Extracts from conversational interviews staged in the spring of 2015:

... what [she] did in her research was to develop [personal ascension moments] into an original and unique proposal about the nature and structure of practice itself, where she talks about the steadfast versatility of the underlying layers of a practice.

[The] other things I am supposed to be doing in the office as a director, like getting projects, and finding work for people and that it was quite reassuring ... that [doing the PhD] coming here and talking about the work, that there was a way to generate projects in the office.

There is a designer building buildings, parallel to that a curator, also doing installations, then I realized that the practice doesn't end there, there are a lot more instruments that I can actually try to play. I became very active in the media. I also started teaching, etc. etc. I later started working for the European Commission and began to understand to understand how many ways practice can work. 
Surely this type of positioning must have an effect on the types of research you can do through architectural creative practice?

Accepting that architectural practice can take place over a broad field has implications with regard to architectural creative practice research. Not least since it can allow ACPR to move beyond research into design/buildings/architects (what architecture is) toward the intentions, negotiations, strategies and actions of practice (what architecture can do).

The research presented in this paper forms part of a larger project and Europe-wide network dedicated to creative practice research. The Architecture, Design and Art Practice Training-research Initial Training Network (ADAPT-r ITN) operates across Europe with strong ties to the Royal Melbourne Institute of Technology (RMIT). It is a $\mathrm{PhD}$ model that supports experienced practitioners in researching their own practice. Adapt-r ITN is inspired and informed by the RMIT's PhD by Invitation.

When Leon van Schaik established the RMIT's PhD by invitation in 1986, the goal was to allow, 'practicing architects to present their own work as the subject of a PhD.' (BD 2012) Over the course of three or four years, candidates attend reviews every six months. During these symposia, they articulate their methods and motivations. In order to gain the $\mathrm{PhD}$ they are required to stage an exhibition, submit a 40,000-word thesis and undergo a viva. Given that the programme has now been underway for almost thirty years, they have a great deal of experience in the subject of creative practice research and it is this knowledge that is currently being shared and developed within in the ADAPT-r ITN.

ADAPT-r ITN is an EU funded PhD practice research partnership established between the RMIT and: Aarhus School of Architecture, Denmark; Estonian Academy of Arts, Estonia; Glasgow School of Art and University of Westminster, UK; KU Leuven, Belgium; RMIT Europe, Spain and the University of Ljubljana, Slovenia. The ambition for the network is that, 'The research that is produced through the ADAPT-r ITN will contribute to a wider research effort to increase knowledge, understanding and quality of research in creative disciplines and its methods.' (ADAPT-r 2013) ${ }^{5}$

The $\mathrm{PhD}$ by practice may be regarded as an attempt to frame the various forms of knowledge in practice in such a way that this knowledge can be shared and, in turn, inform future practice. It can be summarised as: a will to look at practice and see

5

Our role as researchers within the partnership is to look broadly across the doctoral projects of the various researcher/practitioners, with a view to developing a greater understanding of the $\mathrm{PhD}$ by practice and the types of knowledge that this kind of research can both require and produce. Where the ADAPT-r ITN seeks to span architecture, design and art, the research developed for this paper focuses primarily on architecture or more specifically ACPR. This reflects our experience and interest as researchers trained initially in architectural practice, but it is also influenced by the development of the ADAPT-r network, where the initial PhD candidates recruited have been primarily architects and landscape architects, although the newer doctoral candidates recruited also come from other fields. 
things differently (Sullivan 2007, 1191). The model rejects traditional hierarchies of knowledge that give primacy to numbers and words as ways of making propositional knowledge claims, and seeks to understand knowledge in the intentions, actions and outcomes of practice (Niedderer 2007). It follows the assertion that creative practice research has value and that this value is not necessarily best expressed through existing qualitative or quantitative methodologies. Indeed, it can be suggested that these more traditional methodologies do not add anything to the creative practice research process, beyond translating it into a less meaningful form.

\section{Voice 2:}

It's been interesting interviewing some of the practitioners doing the PhD. For instance, a lot of the things they say... a lot of the anecdotes overlap. They are repeated in slightly different ways and from different points of view, until they become like fables: hundreds of forgotten models arrayed on trestle tables, an outburst of rage in response to a mention of Heidegger ... not only are there common stories, there are also common phrases. Or overlapping phrases, whereby 'you are the master', when repeated by the person who was told he was 'the master' becomes, 'I am the man'.

It seems like the group are developing a shared identity through talking and the sharing of stories. And perhaps that's not so strange. After all, the act of sharing stories and making meaning together can be a way of developing agency. It refers to the meanings that people develop and share through experience.

The ADAPT-r model supports the notion that knowledge need not simply be an outcome of research, but that the practitioner/researchers have already developed knowledge over the years, through their engagement in practice. This knowledge is the competence, or input knowledge, that they bring to the $\mathrm{PhD} .{ }^{6} \mathrm{It}$ is through their

\section{6}

Sometimes they do not appreciate the value in the breadth of their own practices Extracts from conversational interviews staged in the spring of 2015.

people do this strange thing, where they blank out large areas of what they actually do.

As designers ... it really bizarre that you feel after 15 years of [practice] you've just responded to people calling you up. And that's ridiculous, how did we get to this point? Because of course you look back and you've made things happen, you've addressed things in certain ways, there are people who have elected to phone you up because of what you've done before, there is all sort of stuff that you just, you edit out of life.

Obviously, they know they do it, but they don't see it as an important part of their practice. 
various competences that the practitioner/researchers can develop innovative new experiences, artefacts and/or transformations, which can, in turn, be framed, with regard to the role of the practitioner/research, in ways that allow for the explication of practice specific knowledge.

\begin{abstract}
Voice 3:
It's certainly a different culture, from both the architectural practice education we both began in, and then the research culture we both seem to have imbibed while developing our $\mathrm{PhD}$ research. Here, well, I suppose there is a tighter network, and the references that are used remain within that tight network. A sort of shared oral tradition has been developed over the last decade of developing the ACPR doctorate amongst this group - but a lot of things remain tacit, because of this 'shorthand' of the fables, the anecdotes.
\end{abstract}

\title{
From Tacit and Explicit to Relational Knowledge
}

Key to an understanding of knowledge production through ACPR is an appreciation of tacit knowledge. This unspoken form of knowledge may be expressed through actions taken in practice. In order to begin to understand the tacit, moves can be taken to explain its actions, effects, operations, processes and implications. These reflections on practice are attempts to translate tacit knowledge into something codifiable. (Schön 1983) However, the will to extract knowledge in this way is problematic, since it implies that tacit and explicit knowledge are two distinct things. They are however, not two separate things, but co-dependent; neither one can operate without the other.

It is virtually impossible and also meaningless to separate codified (or explicit) knowledge from tacit knowledge- each one is needed to instantiate the other, tacit knowledge is inscribed into the artefacts of codified knowledge [...] and, in turn, these artefacts are always present in the act of thinking in action (Amin \& Cohendet, 2004, 95)

Since tacit and explicit knowledge are essential to each other, it can seem that there is perhaps little sense in trying to define what is tacit and what is explicit, instead knowledge can be viewed more broadly, as something that is produced in-between, or as a result of, the tacit and the explicit. ${ }^{7}$

\footnotetext{
7

However, the question of making knowledge explicit comes back into focus when we question the involvement of practice in research. The outcome of research - 'systematic inquiry to the end of gaining new knowledge' - is commonly expected to be propositional knowledge (Niedderer 2007, 5). Niedderer also notes the entwined and mutually dependent relationship of forms of tacit and explicit knowledge, but formulates this relationship more specifically in terms of the elements of knowledge which elude articulation.
} 
With this in mind, the question of doing ACPR becomes one of navigation. How is knowledge communicated, translated and mediated across the broad field that is practice? $^{8}$

Furthermore, by applying this expanded view of knowledge production to architectural practice, it is possible to bridge the perceived divide between design practice and other aspects of practice. Rather than thinking of design as something that is generated through practice, design can be seen to pervade everything that an architect does, in much the same way that tacit operations are present in every piece of, so called, codified knowledge.

Given that tacit knowledge supports and prompts codified knowledge and vice versa, it is clear that there is also knowledge expressed, promoted or produced in the various relationships between tacit and codified knowledge. As such, knowledge may be understood to be multiple. This multiplicity has the potential to be confusing, which is why the role of the researcher/practitioner is critical. In order to effectively explicate knowledge the research/practitioner can frame his/her role within the research. This act of role framing may be key to ACPR, since it a means by which to explicate knowledge relationally with regard to the researcher/practitioner and expanded field of practice. It positions the researcher/practitioner in specific locations and time and supports the contextualisation of intentions and actions in practice. Role framing does this by supporting the research/practitioner in asking the question: How do I engage, act and respond and in what medium do I perform these operations?

The question of media is critical, since it is through the acts of drawing/making/speaking/writing that the researcher/practitioner translates his/her intentions and mediates with the world through practice. Understanding practice as a means of translation and mediation in specific situations suggests that the time in which these actions happen is also critical. There is a temporal aspect to considerations of ACPR. Following on from Mihaly Csikszentmihalyi's (1996) question: when is creativity? It is possible to ask (not what is practice? but) when is

8

The broad field of practice

Extracts from conversational interviews staged in the spring of 2015:

[The idea of disciplinary knowledge] limits the way one describes oneself. I sort of blundered into being an architect, by chance. Actually, I'm interested in something that is slightly to the edge of architecture, infrastructure and a bit of landscape. I'm at one end and I'm not particularly interested in the other end. The envelope [imposed by disciplinary knowledge] is getting smaller and smaller, the more we self-define - are we are doing this, actually no we are doing this little bit in that bit - we limit our ability to broaden [knowledge] out as generalist intelligence.

I think [practice is] about all sorts of things: teaching, directing, design review. Actually, I think it is all the same thing. 
practice? This shift in questioning understands practice to be responsive and relational, not classic and timeless.

Indeed, as Graeme Sullivan (2007, 83) states (whilst discussing Mihaly Csikszentmihalyi), 'creativity [is] not something [...] contained within the head and heart of a person, but [...] an outcome [...] given meaning by what others [have] to say about it.' Furthermore, as Frank Blacker asserts, 'knowing should be studied as practice, and practice should be studied as activity that is rooted in time and culture'. $(1995,63)$

As such, the knowledge that can be developed through ACPR is socially constructed in both context and time and these social constructions (multiple knowledges) are framed (or given meaning) in direct regard to the role of the researcher/practitioner. Whilst there are many forms of knowledge to be found in and around design processes, ACPR is about more than the design of buildings. Practice goes well beyond design (or a traditional understanding of what design is) and reaches toward knowledge, which is neither fixed nor singular, but context specific and relational.

\section{Knowing through/in conversations}

Understanding that knowledge production in ACPR can be context specific and relational suggests that it is also inherently spatial and social. In turn, knowledge can be generated through communication:

knowledge is not simply communicated between actors (human and mechanic), but is generated through communication - speech acts, conversations bodily gestures, glances, expressions, data exchanges, machine to machine interactions, are the relational iterations through which we know, understand, and learn. (Amin \& Cohendet 2004, 67)

These communications can be understood as conversations that develop and reveal relationships between actors. They operate socially, in both context and time, by creating common links and interactions across the field of ACPR. As such, a conversation is not simply two people talking, but the negotiation of relationships and conversations can be operationalized with a view to explicating knowledge through ACPR.

This view of conversation supports the idea that understandings of context/spatiality do not necessarily develop when visiting or experiencing a space (even although that can be a factor), but rather that conversations can link actors across a field that is both temporal and spatial, in such a way that knowledge may be developed somewhere else entirely and at a different time, through the act of investigating and developing relationships in conversation. (McFarlane 2011, 7) 


\section{Voice 1:}

So, talking may relate to an encounter, a dialogue, a narrative, a shared story or a personal interpretation. But it is not just a matter of interpretation. Talking can also be a critical act. It can relate to both history and context.

But talking about architecture does something more. Talking about architecture is not just about interpretation and critique, but also about creating frames or forms, which can result in new experiences or events. As such, talking about architecture can, ironically enough, include the unspoken (or the tacit).

\section{Voice 2:}

As an example, perhaps we can go back to the shared stories and interpretations that the practitioners told me about. These are events that once described and repeated, become references, they become so familiar that they don't need to be spoken about any more. In turn, they become codes or ways of understanding things. Perhaps the same thing happens in practice, by talking about design, you then develop a language that is also partly unspoken, repetitions, references, gestures, looks, whatever... and this can inform the design process.

\section{Voice 1:}

And so, in the act of saying something about something, you frame your relationship to that thing. It's a means of positioning yourself, in relation also to others... the people or media, say, that you are designing with. And so, in a conversation, we are negotiating relationships between others and ourselves.

With regard to the expanded field of ACPR, this liberates the practitioner/researcher in his/her research, since it moves on from the idea that knowledge is to be found in the person, process and/or product. Knowledge can be produced and expressed relationally through conversations. Furthermore, a knowledge generating conversation can be: written, spoken, physical, designed, artefactual, and/or virtual.

\section{Talking - Conversations about ACPR, the PhD \& Practice Research Symposia (PRS)}

In order to achieve the qualification of PhD through the ADAPT-r/RMIT model of creative practice research, the researcher/practitioner is asked to talk about his/her own practice. These discussions are framed with regard to the discipline(s) that the practitioners chose to align themselves with. So, in the case of an architect, they are 
asked to talk about architectural practice, or rather their own architectural practice. The discussions are framed by disciplinarily, not to restrict the research in anyway, but to contextualise it.

The PhD programme operates through a series of symposia, called Practice Research Symposia or PRS, at which the practitioner/researchers are asked to present their work and receive formal feedback from a specially assembled panel and, when there is time, the audience. These presentations may be liked to 'architectural crits' held at schools of architecture across the world, however, rather than being a method for learning architecture, they are a means of talking about architectural practice and trying to explicate knowledge from established practitioners in and amongst peers.

As the practitioner/researchers progress through a number of symposia, they invariably find that the way in which they talk about their practice changes. ${ }^{9}$ It is this change in approach, which suggests that, by talking about practice, they are beginning to position themselves and define their own role in the research. In other words, they are seeing things differently.

Where the formal aspects of the PRS, which are deliberately and strictly choreographed, provide opportunities for the practitioner/researchers to position themselves through talking, there are also informal interactions, which can result in conversations. These spontaneous conversations allow relationships to be explored and developed, in a less structured way, amongst those practitioner/researchers who choose to talk to each other.

It would seem that the act of talking is critical in these PRS situations, since it is by talking that the practitioner/researchers negotiate with each other. So where one could argue that ACPR involves drawing, modelling and writing, talking about these

9

Changing the way you talk

Extracts from conversational interviews staged in the spring of 2015:

'Even the first time we presented there was a shift [...]. you have a way of presenting, you have a story you tell about your practice, you tell about the way that you work. We had that story and we went to the first PRS and it was shot down immediately. Like, [the] rug pulled out from underneath us. And that was brilliant! [...] when you're standing at the front and you're talking about vernacular architecture and all this, they just straight away said "Its nothing to do with vernacular architecture you need to stop talking about that."

'There was the occasion of a visit to [a building]. And I was profoundly struck by a certain detail. And that changed how I thought about the work completely. And then by consequence sort of changed how we're thinking about our work. But I didn't really understand it until - and I still don't really understand it actually - but each time I think about it for each PRS it seems to [arrive?] back and there is some other way to view it.' 
drawings, models and texts, both formally in presentation and informally over coffee can help the practitioner/researchers to develop knowledge in relation to each other.

\section{Conclusion}

There is, it seems, knowledge in conversations. These conversations are, in turn, not limited to artefacts and texts that the practitioners bring with them, they also include thoughts on practice, strategies, anecdotes. Furthermore, a lot of the practitioner/researchers come to the $\mathrm{PhD}$ not really knowing what the $\mathrm{PhD}$ is and it is through talking, both with their peers and their supervisors that they begin to take a stance on what type of $\mathrm{PhD}$ they want to do and how that $\mathrm{PhD}$ might relate to their own varied forms of practice.

\section{Voice 1:}

Where you may think architecture is the act of designing buildings, there is a lot of talking that goes into it. But, we don't really talk about that much when we think about architecture.

\section{Voice 2:}

I guess that begins to demonstrate the difference between what architects do and what they say that they do.

As such, talking is a way for them to mediate their own approach to research. Perhaps this is common to many forms of research, but it is particularly useful for architects, since they can be very used to talking about themselves and their practice, through the entrepreneurial aspects of the profession. In order to get commissions, a lot of architects have learnt how to talk 'a good game' (Jones and Livne-Tarandach, 2008). The challenge then for ACPR is seeing how this skill might be transferred toward the production of knowledge.

In turn, once knowledge is understood not be required to be either tacit or codified, but also a means of creating meaning through connections made relationally, then the value of shaping and exploring relationships through talking becomes clear. As such, the non-design elements of practice are critical and that the idea of primacy (either of the written word or design) can be put aside, in favour of exploring knowledge developed through connections and relationships in context.

By considering ACPR as a means of producing knowledge through developing connections and relationships, knowledge can be explored, prompted and produced which is not necessarily weighted toward design, or the notion that knowledge is the preserve of the male hero-genius. Furthermore, patriarchal tendencies in architecture no longer represent the diversity and scope that could be supported by profession. Indeed, with the free availability of media technology and information, the role of 
architect has changed, not only with regard to who is in charge, but also with regard to who is an expert.

As of today, the profession remains in a state of flux, which means that the various potential roles of ACPR are not yet fully defined. This gives us a chance to think about the future and the role of research in practice. It may be suggested that there is no need to separate research from practice, the two can inform, inspire and support each other. In order to discover the full potential of ACPR, we would need to start a conversation. Indeed, it is through talking about architecture that we might begin to explore knowledge production through architectural creative practice research.

\section{Acknowledgements}

The research leading to this invention has received funding from the People Programme (Marie Curie Actions) of the European Union's Seventh Framework Programme (FP7/2007-2013) under REA grant agreement $n^{\circ} 317325$.

\section{References}

ADAPT-r. (2013) 'Homepage', [online]. Available at http://adapt-r.eu. Accessed May 2015

Amin, A., \& Cohendet, P. (2004). Architectures of knowledge. Oxford, UK: Oxford University Press

BD. (2012) 'Building a body of research', [online]. Available at http://m.bdonline.co.uk/5046701.article?mobilesite=enabled. Accessed 20 July 2013

Blackler, F. (1995). 'Knowledge, knowledge work and organizations: an overview and interpretation', Organization Studies, vol. 16 no. 6, 1021-1046

Csikszentmihalyi, M. (1996). Creativity. New York: HarperCollins

Cuff, D. (1991). Architecture: The Story of Practice. Cambridge, Mass.: MIT Press

Dobson, A. (2014). 21 things you won't learn in architecture school. London: RIBA Publications

Edwards, M., Campkin, B., \& Arbaci, S. (2009). Exploring Roles and Relationships in the Production of the Built Environment. Transactions, 6(1), 38-61 
Forlati, S., Isopp, A., \& Piber, A. (2011). Wonderland manual for emerging architects. Vienna: Springer

Frayling, C. (1993). Research in art and design. V: Royal College of Art: Research Paper, 1 (1)

Fry, T. (2015). In conversation at, Design Education: What do you see? What do you think about it? What do you make of it? University of Ljubljana, 22 April 2015

Gardner, H. (2011). Creating minds: An Anatomy of Creativity Seen Through the Lives of Freud, Einstein, Picasso, Stravinsky, Eliot, Graham, and Gandhi. New York: Basic Books

Gutman, R. (1988). Architectural practice: A Critical View. New York, N.Y.: Princeton Architectural Press

Jones, C. \& Livne-Tarandach, R. (2008). 'Designing a Frame: Rhetorical Strategies of Architects'. Journal of Organizational Behavior 29 (8), 10751099

Lawson, B. (2008). How designers think: The Design Process Demystified. Oxford: Elsevier/Architectural

McFarlane, C. (2011). Learning the city: Knowledge and Translocal Assemblage. Malden, Mass: Wiley-Blackwell

Meades, J. (2012). Museum without walls. London: Unbound

Miessen, M., \& Basar, S. (2006). Did someone say participate? An Atlas of Spatial Practice. Cambridge, Mass.: MIT Press

Niedderer, K. (2007). 'Mapping the Meaning of Knowledge in Design Research'. Design Research Quarterly, 2(2), 1-13

RIBA. (2006). Good Practice Guide: Starting a practice. London: RIBA

RIBA. (2010). Good Practice Guide: Marketing your practice. London: RIBA

RIBA. (2013). RIBA Plan of Work 2013: Overview. London: RIBA

Rose, J. (2013). The Building After: Toyo Ito interviewed by Julian Rose. Artforum, September 2013 
Schön, D. (1983). The Reflective Practitioner: How Professionals Think in Action. Basic Books: New York

Sullivan, G. (2011). Creativity as Research Practice, International Handbook of Research in Arts Education, London: Springer

Till, J. (2009). Architecture depends. Cambridge, Mass.: MIT Press

Till, J., \& Wigglesworth, S. (1998). The Everyday and Architecture. London: Architectural Design

Van Schaik, L. \& Johnson, A. (2011). Architecture and Design: By Practice, By Invitation: Design Practice Research at RMIT. Melbourne: onepointsixone

Eli Hatleskog trained and practiced architecture in the UK, before joining a multidisciplinary research group supporting the planning of Norway's first carbon neutral suburb, where she investigated sustainable lifestyles and behaviors through practice-based research relating to live public projects, exhibitions and workshops. She is currently based at the University of Ljubljana as an ADAPT-r researcher, studying the public interactions of the practitioner/researchers in the network.

Email: eli.hatleskog@,fa.uni-lj.si

Anna Holder trained in architecture and planning in the UK and has practiced in the UK and the Netherlands. She is currently a Postdoctoral Research Fellow at Aarhus School of Architecture, Denmark, and a Director at social enterprise architecture practice Studio Polpo. Her research interests focus around critical spatial practice and the micropolitics of the production of the built environment, social innovation, participatory urbanism and methodologies of practice-based research.

Email: anna.holder@aarch.dk

Anthony Hoete is a New Zealand trained architect practicing in London. He is a founding partner of WHAT architecture and currently in the final stages of a PhD by practice with the RMIT. Through his doctoral research, he has been looking at what his practice actually does, given that only $10 \%$ of their projects have actually been built. His research interests lie in studying the negotiations, rules and communications in practice, with a view to understanding the gameplay of architecture.

Email: hoete@whatarchitecture.com 